Editorial

\title{
Avances tecnológicos en los tratamientos con radioterapia
}

Desde la utilización de los Rx para el tratamiento del cáncer hace más de un siglo hasta nuestro días, se ha recorrido un largo camino con distintas etapas más o menos afortunadas, pero aún así de todas ellas se ha obtenido un gran aprendizaje, aportando las bases necesarias para alcanzar el desarrollo actual. Así pues, en los últimos años los progresos llevados a cabo en el campo informático, el gran desarrollo de la tecnología de la imagen así como el gran conocimiento de la bases moleculares del cáncer, han conducido a la Oncología Radioterápica a ser una terapéutica mucho más eficaz frente al cáncer y el concepto básico del tratamiento radioterápico de administrar la dosis prescrita en el tumor causando los mínimos daños posibles en el tejido normal sigue siendo válida, pero este concepto hoy es mucho más amplio pues, aunque las radiaciones ionizantes pueden controlar la enfermedad locorregional y por tanto curar a un grupo determinado de pacientes, el uso de las mismas asociadas a otras terapéuticas como son los citostáticos, citoprotectores o terapias biológicas, abre un nuevo camino muy esperanzador en el control de la enfermedad cancerosa. Todo este desarrollo ha obligado al Oncólogo Radioterápico a tener un vasto conocimiento, no sólo de lo que le es propio como es la Oncología, sino de la física de las radiaciones, la radiobiología, los mecanismos moleculares de la acción de la radiaciones ionizantes y de su interacción con otros fármacos.

Aunque el tratamiento radioterápico se utiliza de forma locorregional en la enfermedad neoplásica, se ha demostrado que no sólo ha contribuído a la mejora de este control sino que además ha mejorado la supervivencia de los pacientes, como en el cáncer de cabeza y cuello, mama, cérvix, etc. Así mismo, ha contribuído de forma eficaz a mejorar la calidad de vida de los pacientes en el caso de que no sean curables.

En los últimos diez años la Oncología Radioterápica moderna ha progresado en tres direcciones fundamentalmente: avances tecnológicos, mejora del índice terapéutico y el gran conocimiento de la biología molecular y la aplicación de la terapia biológica, aunque este último concepto podría ser incluído dentro de la mejora del índice terapéutico. Dentro del primer grupo podríamos incluir los sistemas de inmovilización, la aplicación de la simulación virtual y planificación tridimensional; los mejores sistemas de control de calidad llamados de imagen portal, el uso ordinario de la radioterapia conformada tridimensional y su máximo desarrollo en lo que denominamos modulación de intensidad de dosis (IMRT); los mejores sistemas de braquiterapia de alta tasa y tasa pulsada; la introducción en un gran número de localizaciones tumorales de la radioterapia intraoperatoria con una mejor explotación de los tiempos de la aplicación terapéutica y las técnicas de radiocirugia y radioterapia estereotáxica intra y extracraneal. Dentro del segundo grupo, mejorar el índice terapéutico, esto se ha basado fundamentalmente en el conocimiento radiobiológico, dando lugar al uso de alteraciones en el fraccionamiento clásico tratando de adaptar el mismo a la biología celular tumoral. También el uso de radiosensibilizadores radioprotectores quimioterápicos, hipertermia, fototerapia y partículas pesadas ha contribuído a mejorar este campo. Y en tercer lugar, no por ser la menos importante, ha nacido una nueva vía de desarrollo, derivada del conocimiento de los fenómenos moleculares que suceden tras una irradiación, tanto en la célula como en el medio intercelular, y que utiliza nuevos blancos que pueden intervenir tanto en la reparación de las lesiones provocadas en el ADN como en la regulación de la apoptosis. 
En este conjunto de avances tecnológicos habría que destacar, por su importancia, la incorporación de las imágenes de tomografía axial computerizada (TAC), de Resonancia Magnética (RM) y de la tomografía por emisión de positrones (PET), así como las técnicas de fusión de imagen que permiten un mejor conocimiento anatómico pudiendo describir con mayor exactitud el volumen tumoral, así como los órganos de riesgo que van a ser blanco de la irradiación. La utilización de estas imágenes tridimensionales, acompañadas del desarrollo informático, así como el uso de nuevos algoritmos de cálculo han permitido desarrollar lo que denominamos planificación tridimensional, que permite el conocimiento de la distribución de dosis en cualquier punto del volumen blanco así como de los órganos de riesgo, pudiendo contar con una nueva herramienta, histogramas dosis volumen (HDV) que permite la comparación de distintos tratamientos, pudiendo el Oncólogo Radioterápico elegir el que considera más eficaz. Así mismo, la aplicación de los conocimientos radiobiológicos a los nuevo sistemas de planificación dan lugar a nuevos conceptos como es TCP (probabilidad de control tumoral) y NTCP (la probabilidad de producir efectos secundarios en los tejidos sanos).

Con el desarrollo actual del PET, así como de la RM espectroscópica, podemos obtener información adicional de la proliferación celular, la actividad del metabolismo tumoral, su oxigenización y vascularización. Este conocimiento puede traducirse en la posibilidad de administrar dosis mayores en las zonas de actividad proliferativa, dando lugar a un nuevo concepto que es la inhomogeneidad de la dosis dentro de un mismo volumen. También está en desarrollo lo que denominamos isodosis biológicas, diseñadas teniendo en cuenta las correcciones necesarias en función del coeficiente alfa/beta de cada tejido, lo que contribuirá sin ninguna duda a un conocimiento mucho más real de la distribución de dosis.

El uso generalizado de lo que denominados radioterapia conformada ha contribuido así mismo a una gran mejora de la calidad de los tratamiento radioterápicos. La posibilidad de utilización de las imágenes de TAC, RM y PET ha permitido la determinación de volúmenes blancos, así como de órganos de riesgo con mayor precisión, dando lugar a la realización de tratamientos muy conformados con protección de los tejidos sanos. La puesta en práctica de esta radioterapia conformada es posible gracias a la utilización de Aceleradores Lineales que disponen de colimadores multiláminas, los cuales se adaptan a la forma tumoral en cada posición de tratamiento. La sofisticación de la radioterapia conformada es lo que hoy denominamos intensidad modulada de dosis (IMRT). Las técnicas de intensidad modulada permiten una distribución de dosis adaptada de forma óptima al volumen tumoral, ya que deposita la dosis por segmentos en lugar de incluir todo el volumen tumoral en el haz de irradiación. Estas técnicas de IMRT se pueden desarrollar en las nuevas máquinas de tratamiento llamadas de Tomoterapia, que utilizan la tecnología del TAC, un gantry circular al que se ha acoplado un Acelerador de $6 \mathrm{MV}$ y que irradia de forma continua.

Estas técnicas de intensidad modula permiten el incremento de dosis hasta niveles prohibitivos para otras técnicas de irradiación, mejorando el control local de algunos tumores como son próstata, cabeza y cuello, etc; pero sobre todo mejora de forma eficaz los efectos secundarios. Este tipo de tratamientos tan sofisticados son más críticos en cuanto a los posibles errores ya que cualquier mínimo cambio en el posicionamiento del blanco puede dar lugar a un error grave en el tratamiento. Así pues, es necesario un control adecuado tanto del posicionamiento del paciente como de los volúmenes diseñados, tanto del tumor como de los órganos de riesgo. Para llevar a cabo este tipo de control los nuevos Aceleradores Lineales disponen de tecnología de Imagen Portal, basada en sales de silicio amorfo, que proporcionan una buena calidad de las imágenes facilitando la verificación del tratamiento.

Los Aceleradores de última generación incorporan nuevas herramientas basadas en tecnología de TAC que permite la adquisición de imágenes volumétricas de cada sesión de tratamiento, pudiendo corregir el posicionamiento del paciente en el caso de que no coincidan las imágenes tridimensionales obtenidas en el TAC de simulación virtual. Este mismo tipo de adecuación al tratamiento puede ser corregido en el sistema utilizado por la Tomoterapia.

La aplicación en los tratamientos radioterápicos de métodos estereotáxicos utilizados en neurocirugía ha da- 
do lugar a un gran desarrollo en el tratamiento tanto de los tumores intracraneales como extracraneales. La utilización de estos sistemas mixtos de estereotaxia e irradiación ha permitido la administración de altísimas dosis en una única fracción a volúmenes reducidos con tasas de control muy elevadas y protección de los tejidos circundantes. Este tipo de tratamiento denominado Radiocirugía es posible realizarlo en Aceleradores modernos que disponen de aditamentos adecuados adaptados, así como en las Unidades denominadas Gamma Knife, cuyo sistema de irradiación está formado por doscientas una fuentes de Cobalto-60 dispuestas convenientemente para irradiar el volumen blanco. Esta misma tecnología permite administrar el tratamiento en varias fracciones y entonces lo denominamos Radioterapia Estereotáxica Fraccionada.

En este afán de mejorar el control local de la enfermedad con la administración de altas dosis de irradiación con preservación de los tejidos sanos se ha incorporado en los últimos años también en el medio hospitalario español, aunque de forma restringida, lo que se denomina radioterapia intraoperatoria (RIO) que consiste en la administración en el seno de una intervención quirúrgica de una única y elevada dosis en el lecho quirúrgico utilizando electrones de un Acelerador lineal. Esta técnica de tratamiento que requiere una adecuada programación así como una eficiente cooperación entre diversos equipos de especialistas, permite además de mejorar el control local de algunos tumores, el dar a conocer a otros especialistas la actividad de alta calidad que se lleva a cabo dentro de los Servicios de Oncología Radioterápica.

Bien es sabido también que la Braquiterapia ha contribuído desde sus inicios al control eficaz de gran cantidad de tumores en estadios iniciales, pero en los últimos años ha habido un avance sin precedentes en el campo de la tecnología aplicada a esta técnica. Los sofisticados nuevos equipos que utilizan fuentes de Iridio-192 monitorizados y dotados de modernos programas informáticos, permiten además de una correcta protección de los profesionales la optimización de la distribución de dosis en el volumen tumoral.

En cuanto a la contribución para mejorar el índice terapéutico se han desarrollado múltiples estrategias pero destacaremos fundamentalmente las alteraciones del fraccionamiento que aunque han contribuido al mejor control local y en algunos casos a mejorar la supervivencia no son técnicas muy extendidas debido a los problemas logísticos que conllevan. Donde sí ha habido un gran desarrollo es en la utilización de diferentes combinaciones de quimioterápicos con la irradiación tratando de potenciar el efecto de esta última. Este tipo de terapéutica ha contribuido, como así lo demuestran múltiples estudios aleatorizados, a la mejora del control local así como la supervivencia de diferentes localizaciones tumorales. Hasta el momento actual la forma más eficaz de diseñar este tipo de terapéuticas es administrando los fármacos de forma concurrente con el tratamiento radioterápico y, hoy en día, las combinaciones de la irradiación con las Fluoprimidinas tanto intravenosas como orales, el Platino y sus derivados, Gemcitabina, Taxanos, etc, forman parte del elenco terapéutico habitual.

En cuanto a la tercera vía, combinación de la irradiación junto con terapias biológicas, podría incluirse dentro del grupo de la mejora del índice terapéutico pero debido al gran auge que está adquiriendo esta nueva vía de desarrollo creo que se merece un apartado especial, pues el Oncólogo Radioterápico debe tener ya incorporado en su bagaje científico los nuevos conocimientos de todos los fenómenos moleculares que suceden a nivel celular tras la exposición de las mismas tanto a las radiaciones ionizantes como a agentes quimioterápicos y biológicos, actuando bien directamente sobre blancos críticos como es el ADN o estimulando distintos sensores y receptores de membrana que dan lugar al desencadenamiento de una cascada de señales a nivel del citoplasma y dirigidas al núcleo que van a intervenir de forma decisiva en el futuro celular tumoral. Así pues, el conocimiento exhaustivo de las vías de señalización y de todos los elementos que intervienen en ella está dando lugar a lo que ya se consideran nuevos blancos terapéuticos selectivos, ampliando el campo de la modulación de los efectos que provoca la irradiación a nivel celular. Además hay que tener en cuenta que una de las características principales de estos nuevos agentes biológicos es la de su poder de radiosensibilización, habiéndose demostrado ya en distintos ensayos clínicos resultados de mejor control en distintos procesos oncológicos. 
Para finalizar este recordatorio de los últimos avances habidos en el entorno de la Oncología Radioterápica quiero dar un pequeño toque de atención sobre una cuestión que, en mi opinión, es muy importante. El gran desarrollo que ha habido en los últimos años a nivel tecnológico y que tanto ha contribuido a mejorar el trabajo y los resultados en el tratamiento de muchos tumores, exige un mayor tiempo de dedicación del especialista en Oncología Radioterápica en el tratamiento de las imágenes en cualquiera de sus posibilidades: diseño de volúmenes, controles de calidad, modificaciones terapéuticas, etc. Esto ha multiplicado, en algunos casos, por un factor de tres este tiempo del especialista. Las nuevas tecnologías para tratamiento con imagen guiada, ya en marcha, van a precisar de una mayor dedicación. Todo este tiempo utilizado en estos menesteres puede ir en detrimento de la formación clínica del especialista en Oncología Radioterápica. Por tanto, creo que la investigación y desarrollo de nuevas tecnologías deben también ir encaminadas al estudio de herramientas que minimicen el tiempo de dedicación del especialista clínico, permitiendo y facilitando el desarrollo de la Oncología Radioterápica en todos los campos, tanto clínicos como tecnológicos.

Alfredo Ramos Aguerri Servicio de Oncología Radioterápica Hospital Ramón y Cajal Madrid 